\title{
Multi-Scale Modeling of a Direct Non-Oxidative Methane Dehydroaromatization Reactor with a Validated Model for Catalyst Deactivation
}

Chirag Mevawala, Xinwei Bai, Goutham Kotamreddy, Debangsu Bhattacharyya*, Jianli Hu

Department of Chemical and Biomedical Engineering, West Virginia University, Morgantown, WV 26506, USA

Key Words

Non-oxidative methane dehydroaromatization (DHA), Fixed bed reactor, Data reconciliation, Dynamic parameter estimation, Catalyst deactivation

* Corresponding author.

Tel:1-304-293-9335, E-mail: Debangsu.Bhattacharyya@mail.wvu.edu 


\section{APPENDIX A}

Temperature profile for conducting the TGA experiment is shown in Figure A.1.

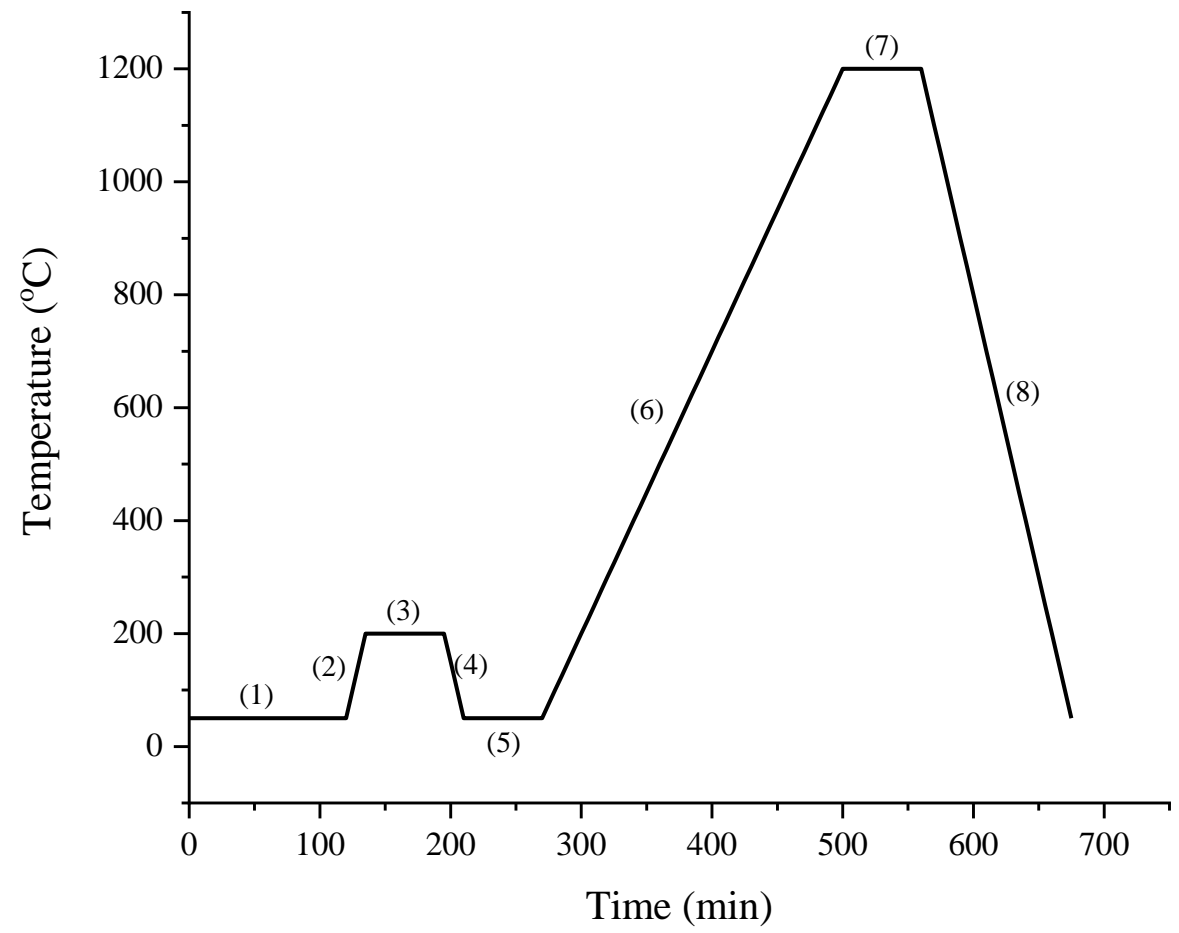

Figure A.1. Temperature profile of thermogravimetric analysis (TGA) experiments

The detail numerical reading for Figure 2 is shown in Table A.1.

Table A.1. Detailed numerical reading of Figure 2

\begin{tabular}{ccccc}
\hline Samples & Initial Weight & $\begin{array}{r}\text { Weight at the End } \\
\text { of Step 6 }\end{array}$ & $\begin{array}{r}\text { Weight at the End of } \\
\text { Step 7 }\end{array}$ & $\begin{array}{c}\text { Total Weight Loss } \\
\text { (mg) }\end{array}$ \\
\hline a & 35.937 & 32.432 & 32.200 & 3.737 \\
b & 33.463 & 29.480 & 29.330 & 4.133 \\
c & 43.350 & 37.694 & 37.526 & 5.656 \\
d & 34.895 & 29.985 & 29.856 & 5.039
\end{tabular}




\section{APPENDIX B}

Data reconciliation for $725^{\circ} \mathrm{C}$ and $750{ }^{\circ} \mathrm{C}$ temperature is shown in Figure B.1.
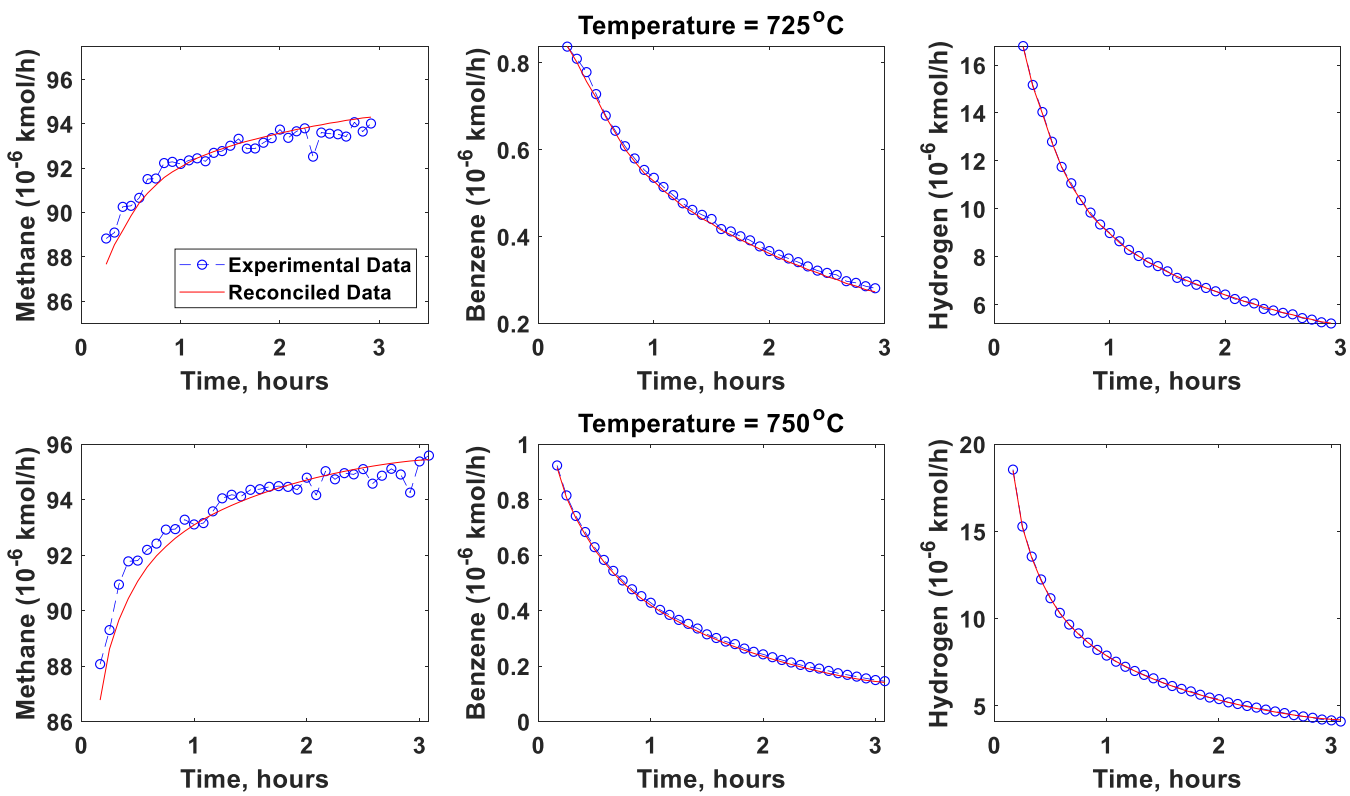

Figure B.1. Data reconciliation plots for $725^{\circ} \mathrm{C}$ and $750^{\circ} \mathrm{C}$ temperature 


\section{APPENDIX C}

The comparison of parameter estimation model result with experimental data for $800{ }^{\circ} \mathrm{C}$ is shown in Figure C.1.
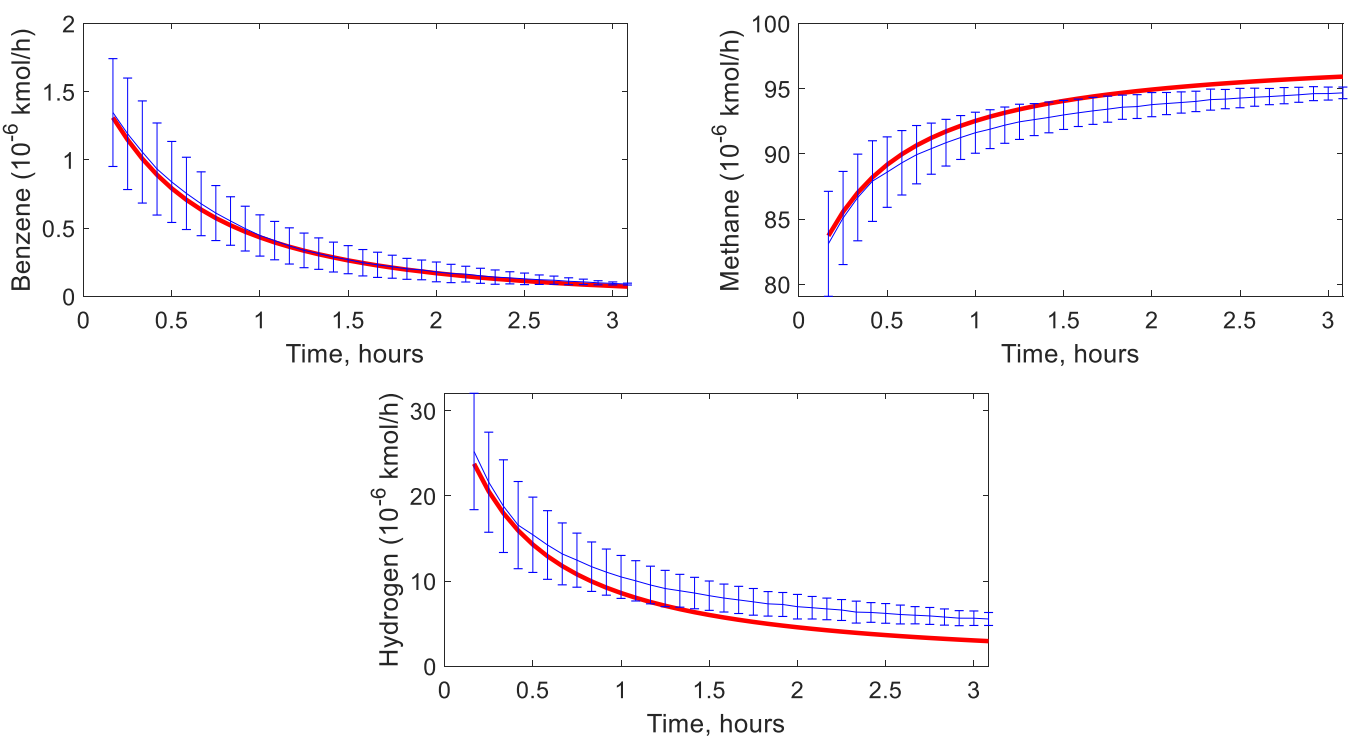

Figure C.1. Comparison of parameter estimation model with experimental data for $800{ }^{\circ} \mathrm{C}$ 


\section{APPENDIX D}

Sample Gantt chart for 2 parallel reactor cyclic operation is shown in Figure D.1. The blue color indicates reactor undergoing methane DHA reaction, black color indicates catalyst regeneration, and green color indicates cooling/preparation time. It should be noted that this is not an optimized Gantt chart. Figure D. 1 shows the Gantt chart for 2 parallel reactor cyclic operation. Here, the total number of reactors required is 4 for continuous operation, and at any given time 2 reactors are undergoing methane DHA reaction.

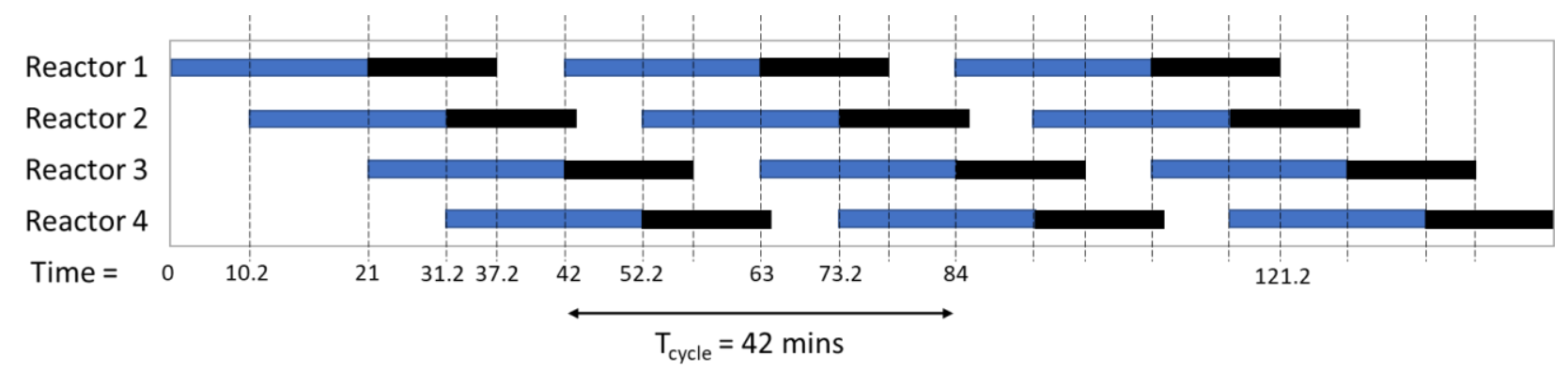

Figure D.1. Gantt chat for 2 parallel reactor cyclic operation 